\title{
Conteúdo de DNA e caracterização anatômica de cultivares de oliveiras (Olea europaea L.)
}

\section{DNA content and anatomical characterization of olive cultivars (Olea europaea $\mathrm{L}$.}

\author{
Thatiane Padilha de Menezes ${ }^{1}$, Adelson Francisco de Oliveira ${ }^{1}$, Moacir Pasqual ${ }^{2}$, Afonso Ricardo de \\ Souza $^{2}$, Evaristo Mouro de Castro ${ }^{2}$
}

\begin{abstract}
${ }^{1}$ Empresa de Pesquisa Agropecuária de Minas Gerais, Rodovia Lavras/Ijaci km 02, Campus da UFLA, Lavras - MG, ${ }^{2}$ Universidade Federal de Lavras - Campus Universitário, Caixa Postal 3037, Lavras - MG. Email: thatiagro@yahoo.com.br
\end{abstract}

Recebido em:28/07/2017

Aceito em:05/12/2017

Resumo: Devido à expansão da olivicultura no Brasil e ao elevado número de variedades existentes, estudos visando a caracterização de cultivares são fundamentais. Objetivou-se com este trabalho caracterizar a morfologia interna, quantificar anatomicamente os tecidos foliares e estimar o conteúdo de DNA de seis cultivares de oliveiras do Banco de Germoplasma da Epamig Sul de Minas. Para o estudo anatômico, folhas totalmente expandidas de oliveiras foram cortadas em secções transversais e avaliadas em relação à espessura da epiderme da face adaxial e abaxial, espessura do parênquima paliçádico e lacunoso, espessura do mesofilo e nervura central. Foram registradas 128 fotomicrografias, sendo 64 do limbo foliar e 64 da nervura central, divididas em quatro repetições. Para a determinação do conteúdo de DNA, aproximadamente $70 \mathrm{mg}$ de tecido foliar juntamente com Glycine Max (padrão de referência interno) foram triturados em placa de Petri contendo $1 \mathrm{~mL}$ de tampão Marie. A suspensão de núcleos foi filtrada através de malha de $50 \mu \mathrm{m}$, sendo corados com adição de $15 \mu \mathrm{L}$ com iodeto de propídeo para cada amostra. Para cada tratamento, três amostras de dez mil núcleos foram analisadas em citômetro Facscalibur (Becton Dickinson). O conteúdo de DNA das cultivares de oliveiras variaram de 2,54 a 2,89 pg. A estrutura básica das cultivares de oliveiras é a mesma, porém, há distinção nas espessuras dos tecidos foliares, na nervura central e no mesofilo.

Palavras-chaves: anatomia quantitativa, citometria de fluxo, banco de germoplasma.

Abstract: Due to the expansion of olive cultivation in Brazil and the high number of varieties, characterization studies of cultivars are fundamental. This study aimed to characterize the internal morphology, quantify anatomically the foliage and estimate the DNA content of six olive cultivars in the Banco de Germoplasma da Epamig Sul de Minas. For the anatomical analysis, fully expanded leaves of olive trees were cut into cross sections and evaluated for epidermal thickness of adaxial and abaxial faces, thickness of palisade and spongy parenchyma and thickness of the mesophyll and midrib. Were recorded 128 photomicrographs, 64 of the leaf blade and 64 of the midrib, divided into four replication. For DNA content, approximately $70 \mathrm{mg}$ of leaf tissue were grounded with Glycine max (internal reference standard) into a Petri dish containing $1 \mathrm{ml}$ of buffer Marie. The nuclei suspension was filtered through $50 \mu \mathrm{m}$ and stained in addition of $15 \mu \mathrm{L}$ with propidium iodide for every sample. For each treatment, three samples of ten thousand nuclei were analyzed on Facscalibur cytometer (Becton Dickinson). The DNA content of olive cultivars ranged from 2.54 to $2.89 \mathrm{pg}$. The basic structure of olive cultivars is the same for different cultivars, however, there are differences concerning the thickness of leaf tissues, the midrib and in the mesophyll.

Keywords: quantitative anatomy, flow cytometry, germplasm bank.

\section{Introdução}

A olivicultura é uma atividade recente e em expansão no Brasil (Oliveira et al., 2009), sendo necessário para seu cultivo a utilização de plantas e mudas certificadas geneticamente, ou seja, que correspondam fidedignamente à 


\section{Revista Agrarian}

ISSN: 1984-2538

variedade que se pretende cultivar, já que a qualidade e a produtividade são intrínsecas do potencial genético de cada variedade (Cançado et al., 2012).

De modo geral, a identificação de acessos ou variedades de oliveira é realizada por meio da análise e comparação de caracteres morfológicos e agronômicos das plantas. No entanto, esse método apresenta algumas restrições em relação à sua aplicabilidade. Por exemplo, em oliveira, restringe-se apenas às plantas desenvolvidas, adultas e, preferencialmente, em fase de florescimento ou frutificação, pois vários aspectos morfológicos estudados durante a identificação somente podem ser observados nessa fase do desenvolvimento ou da reprodução (Cançado et al., 2012).

Uma alternativa para a identificação das plantas é o estudo da morfologia interna. A caracterização anatômica dos órgãos vegetais define peculiaridades estruturais de cada espécie, com aplicação em diversas áreas (Leal-Costa et al., 2008), como a fitotecnia (Silva et al., 2005).

Outra metodologia que também têm sem sido utilizada para caracterização das plantas é a técnica da citometria de fluxo, a qual permite estimar o conteúdo de DNA nuclear de forma eficiente e rápida.

Tendo em vista a falta de informações sobre a anatomia de cultivares de oliveira e a aplicação da técnica de citometria nesta espécie, objetivou-se com este estudo caracterizar a morfologia interna, quantificar anatomicamente os tecidos foliares e estimar o conteúdo DNA das cultivares de oliveiras protegidas do Banco de Germoplasma da Epamig Sul de Minas.

\section{Material e métodos}

Para a instalação do experimento foram utilizadas as cultivares de oliveiras MGS Grapollo 541, MGS Grapollo 561, MGS Mariense, MGS Grapollo 556, MGS Mission 293, MGS Neblina, provenientes do Banco de Germoplasma da Epamig, localizada no município de Maria da Fé, no estado Minas Gerais.

\section{Citometria de fluxo na quantificação do DNA}

Para determinação do conteúdo de DNA foram utilizados aproximadamente $70 \mathrm{mg}$ de tecidos foliar de cultivares de oliveira e de soja (Glycene max - padrão de referência interno). As folhas foram coletadas na estação experimental da Epamig, em Maria da Fé-MG, acondicionados em caixa de isopor com gelo e transportados para o Laboratório de Cultura de Vegetais, no Departamento de Agricultura-UFLA.

Posteriormente, os materiais foram triturados juntos em uma placa de Petri contendo $1 \mathrm{~mL}$ de tampão gelado utilizado para a liberação dos núcleos. A suspensão de núcleos foi aspirada por meio de gaze, com auxílio de pipeta Pauster e filtrada através de uma malha de $50 \mu \mathrm{m}$. Os núcleos foram corados pela adição de $15 \mu \mathrm{L}$ de iodeto de propídeo.

$\mathrm{O}$ delineamento experimental utilizado foi o inteiramente casualizado, com três repetições. Os tratamentos constituíram de seis cultivares de oliveira: MGS Grapollo 541, MGS Grapollo 561, MGS Mariense, MGS Grapollo 556, MGS Mission 293, MGS Neblina. Para cada amostra, dez mil núcleos foram analisados utilizando-se escala logarítmica. A análise foi realizada no citômetro Facscalibur (Becton Dickinson), os histogramas obtidos através do software Cell Quest e analisados estatisticamente no software WinMDI 2.8 .

O conteúdo de DNA nuclear das plantas foi estimado através da fórmula: DNA nuclear da $\operatorname{amostra}(\mathrm{pg})=\underline{\mathrm{G} 1 \text { amostra }} \times$ DNA padrão (pg)/ G1 padrão

Os coeficientes de variação $(\mathrm{CV}) \mathrm{e}$ conteúdos de DNA (pg) obtidos foram submetidos à análise de variância pelo Teste $\mathrm{F}$ e as médias foram agrupadas pelo teste Scott-Knott $(p \leq 0,05)$.

\section{Caracterização anatômica}

Foram colhidas quatro folhas totalmente expandidas no terço superior de cada cultivar de oliveira. Em seguida, foram fixadas em F.A.A.70\% (solução de formaldeído, ácido acético e etanol) por 72 horas e transportadas ao Laboratório de Anatomia Vegetal da Universidade Federal de Lavras, onde ficaram conservadas em álcool 70\% até a confecção das lâminas.

Amostras da região mediana das folhas foram retiradas para o emblocamento em resina. $\mathrm{O}$ material foi submetido à desidratação em série etílica (álcool etílico 70\%, álcool etílico 80\%, álcool etílico comercial 92,8\%, álcool etílico P.A), sendo deixado em cada concentração por duas horas. 


\section{Revista Agrarian}

ISSN: 1984-2538

Posteriormente, foi colocado em solução de pré-infiltração (resina base e etanol 95\%, na proporção 1:1), durante duas horas em vácuo. Em seguida, permaneceu em resina base (solução de infiltração) por 48 horas. Após este processo, o material foi transferido para moldes de polietileno contendo solução de polimerização (resina base/endurecedor 15:1) e desemblocados no dia seguinte.

Os cortes realizados foram em secção transversal com $10 \mu \mathrm{m}$ de espessura em micrótomo semi-automático. $\mathrm{O}$ material foi corado com azul de toluidina $0,05 \%$ e as lâminas montadas em verniz vitral incolor $500 \AA$.

As características estudadas foram as espessuras da epiderme da face abaxial e adaxial, as espessuras do parênquima paliçádico e parênquima esponjoso, do mesofilo e a espessura da nervura central.

As observações das secções anatômicas foram realizadas em microscópio Olympus CX41 acoplado a câmara digital Belcam DIV-3000. Foram registradas 128 fotomicrografias, sendo 64 do limbo foliar e 64 da nervura central, divididas em quatro repetições.

As medições das fotos foram feitas no software ImageJ (domínio público). Os dados foram submetidos à análise de variância e as médias comparadas pelo teste de Scott-Knott (5\%) por meio do programa estatístico Sisvar (2000).

\section{Resultados e discussão}

\section{Conteúdo de DNA}

Os valores do conteúdo de DNA e o coeficiente de variação (CV) das cultivares estudadas estão apresentados na Tabela 1.

É possível verificar que três grupos foram formados em relação ao Índice de DNA (ID) (Tabela 1). As cultivares MGS Grapollo 556, MGS Grapollo 541 e MGS Mariense apresentaram maior quantidade de DNA, diferentemente da cultivar MGS Mission 293, com o menor ID. As demais cultivares apresentaram conteúdo de DNA intermediário.
Pelos dados obtidos infere-se que os conteúdos de DNA das cultivares de oliveiras apresentaram uma amplitude de 2,54 a 2,89 pg DNA. Loueiro et al. (2007) determinaram pela técnica de citometria de fluxo o conteudo de DNA nuclear de cultivares de oliveira (Olea europaea var. europea) e encontraram uma variação de 2,90 $\pm 0,20$ pg (cv. Verdeal) a $3,07 \pm 0,018$ pg (cv. Santulhana).

Tabela 1. Índice de DNA (ID) e Coeficiente de Variação (CV) para cultivares de oliveiras.

\begin{tabular}{lcc}
\hline Cultivar & ID Pico 1 & CV (\%) \\
\hline MGS Mission 293 & $2,54 \mathrm{c}$ & $0,64 \mathrm{c}$ \\
MGS Neblina & $2,67 \mathrm{~b}$ & $0,92 \mathrm{~b}$ \\
MGA Grapollo 561 & $2,70 \mathrm{~b}$ & $0,93 \mathrm{~b}$ \\
MGS Grapollo 556 & $2,80 \mathrm{a}$ & $1,06 \mathrm{a}$ \\
MGS Grapollo 541 & $2,83 \mathrm{a}$ & $1,20 \mathrm{a}$ \\
MGS Mariense & $2,89 \mathrm{a}$ & $1,19 \mathrm{a}$ \\
\hline
\end{tabular}

Médias seguidas pela mesma letra na vertical pertencem a um mesmo grupo e não diferem entre si pelo teste de Scott-Knott ao nível de 5\% de probabilidade.

A variação na quantidade de DNA, de acordo com Williams et al. (2002), pode ocorrer devido a pequenas ampliações ou deleções de sequências de DNA nos cromossomos durante a hibridação.

A confiabilidade das análises de citometria de fluxo foi baseada nos CVs. Galbraith et al. (2001) e Marie e Brown (1993) relatam ser este um critério fundamental e que reflete na qualidade da metodologia utilizada. Um $\mathrm{CV}<5 \%$ é estabelecido por Galbraith et al. (2002) como critério de aceitação. Neste estudo observa-se um CV abaixo do estabelecido pela literatura, demonstrando qualidade dos resultados obtidos.

Os histogramas obtidos pela citometria de fluxo estão apresentados na Figura 1. Dois picos são observados nos gráficos representando a fase G0/G1 do ciclo celular. O pico 1 refere-se ao pico da amostra e o padrão ao da soja (referência interna). 


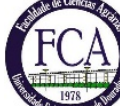

\section{Revista Agrarian}

ISSN: 1984-2538
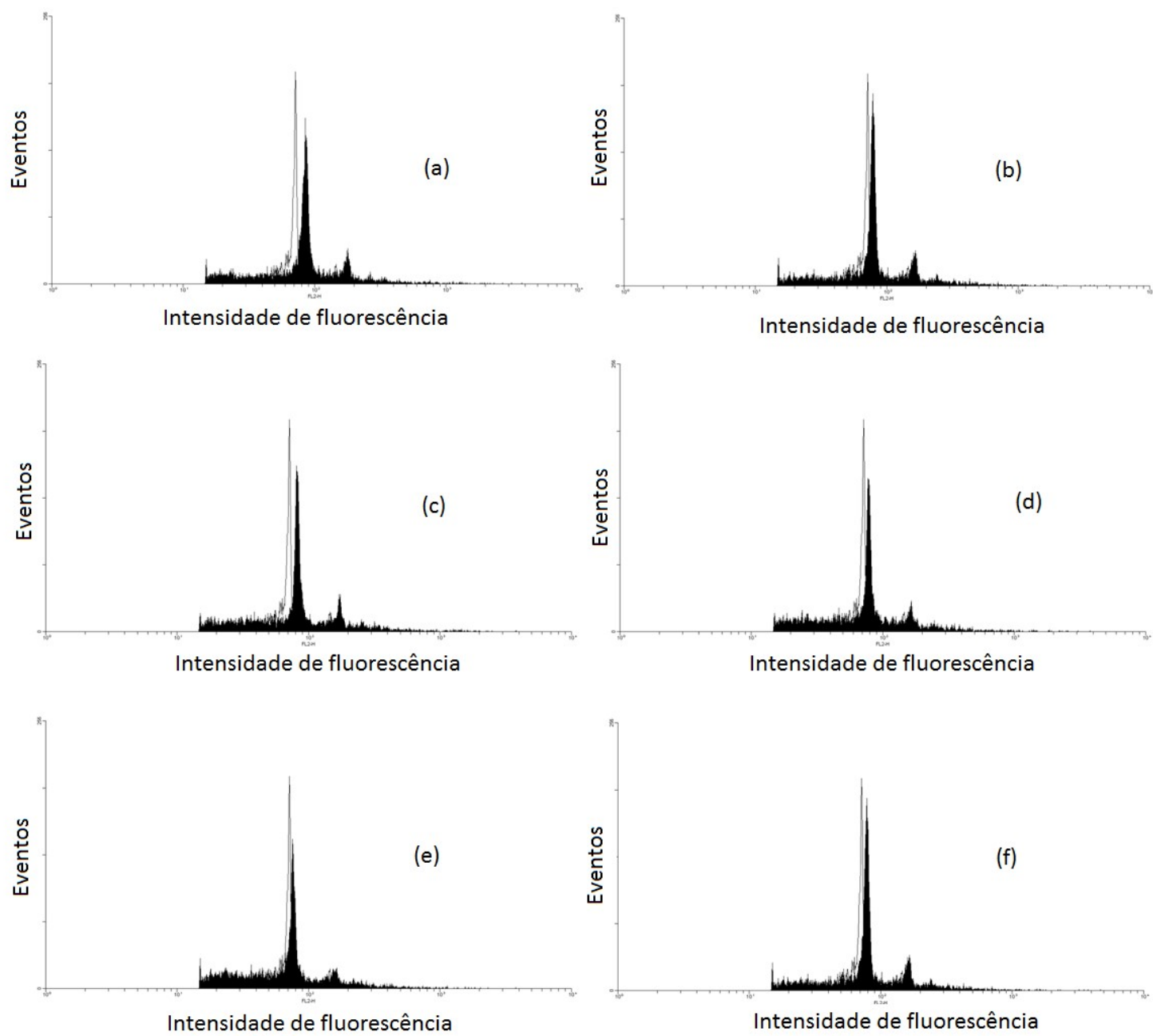

Figura 1. Histogramas de citometria de fluxo de cultivares de oliveiras juntamente com a soja utilizada como padrão de referência. (a) MGS Grapollo 541 (b) MGS Grapollo 561 (c) MGS Mariense (d) MGS Neblina (e) MGS Mission 293 (f) MGS Grapollo 556.

\section{Caracterização morfoanatômica}

As folhas das cultivares de oliveira apresentaram estrutura básica semelhante, com epiderme unisseriada em ambas as faces, abaxial e adaxial (Figura 2). Imediatamente a epiderme da face adaxial encontra-se o parênquima paliçádico, caracterizando esta espécie como dorsiventral.

O parênquima paliçádico apresenta células alongadas, dispostas normalmente em três camadas. O parênquima esponjoso é formado por várias camadas com células de formato irregular.

A nervura central tem secção convexa, com epiderme visivelmente mais espessa na face adaxial, embora não tenha sido medida. Subjacente à epiderme nas faces abaxial e adaxial notam-se camadas de colênquima. $\mathrm{O}$ feixe vascular é colateral, situa-se no parênquima fundamental e em formato de arco (Figura 3). 


\section{(2) \\ Revista Agrarian}

ISSN: 1984-2538
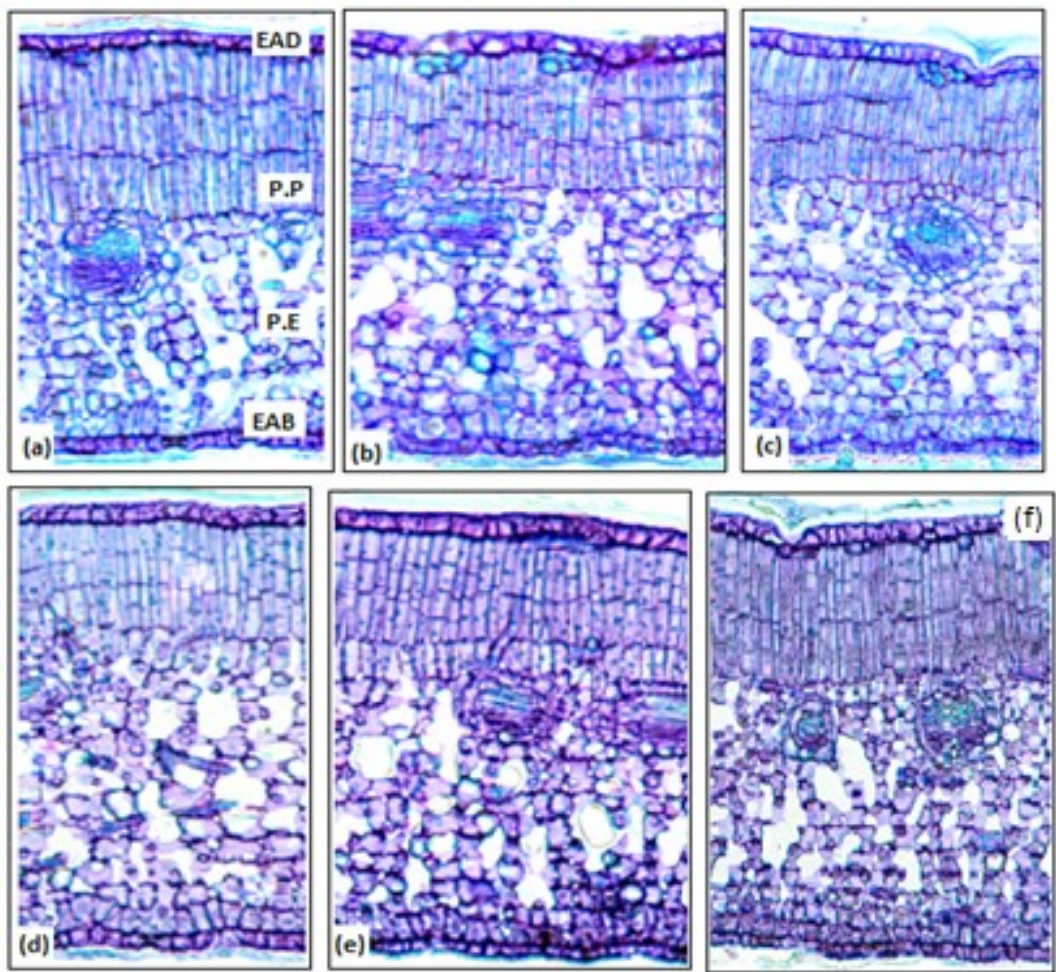

Figura 2. Seccções transversais de folhas de seis cultivares de oliveiras. (a) MGS Mariense,(b)MGS Mission 293, (c) MGS Grapollo 561, (d) MGS Grapollo 541, (e) MGS Neblina, (f) MGS Grapollo 556. EAD = epiderme face adaxial, $\mathrm{EAB}=$ epiderme face abaxial, $\mathrm{PP}=$ parêquima paliçádico, $\mathrm{PE}=$ parênquima esponjoso.
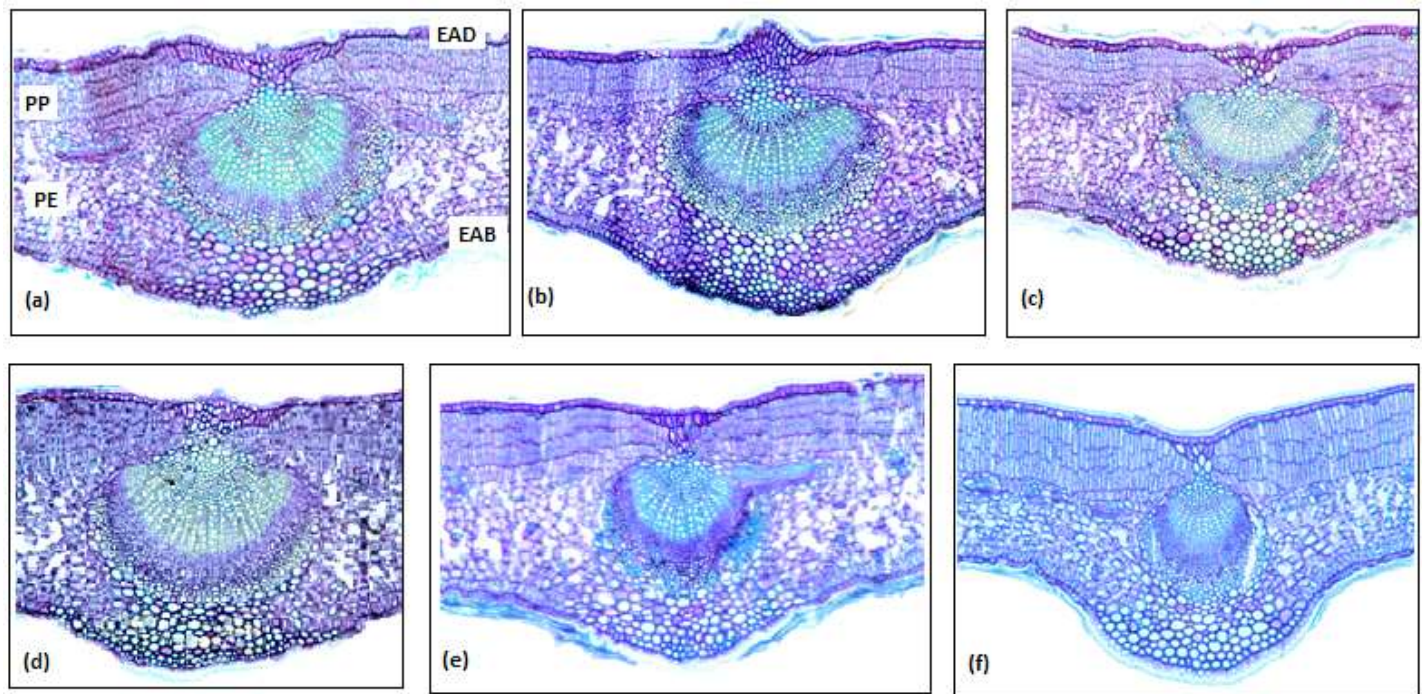

Figura 3. Secções transversais da nervura central de folhas de seis cultivares de oliveiras. (a) MGS Grapollo 556, (b) MGS Neblina, (c) MGS Grapollo 541, (d) MGS Grapollo 561, (e) MGS Mission 293, (f) MGS Mariense. EAD = epiderme face adaxial, $\mathrm{EAB}=$ epiderme face abaxial, $\mathrm{PP}=$ parênquima paliçádico, $\mathrm{PE}=$ parênquima esponjoso. 


\section{Revista Agrarian}

ISSN: 1984-2538

Os dados da anatomia foliar revelaram diferenças para todas as características avaliadas (Tabela 2). Para a epiderme da face abaxial foi verificado maiores espessamentos para as cultivares MGS Grapollo 541, MGS Grapollo 561, MGS Mission 293.

Já para a face adaxial, a epiderme foi mais espessa nas cultivares MGS Grapollo 556 e MGS Grapollo 561. Para Castro et al. (2009) a espessura da epiderme adaxial pode estar relacionada com as condições de intensidade de radiação ou as condições hídricas. Logo, as cultivares acima citadas podem ser mais resistentes ao déficit hídrico e a alta luminosidade.

Estudos relacionando modificações anatômicas de azeitonas cultivados sob estresse salino foram realizados Moretti et al. (2017). Os autores relataram que as plantas de oliveiras cultivas sob $60 \mathrm{mM} \mathrm{NaCl}$ exibiram nos frutos aumento significativo da cutícula, epiderme, hipoderme e mesocarpo.

Quanto à espessura do parênquima paliçádico foram observados maiores espessamentos para as cultivares MGS Grapollo 556 e MSG Grapollo 561 e MGS Mariense. A espessura deste tecido é uma importante característica associada à proteção foliar contra alta intensidade luminosa (Tuffi Santos et al., 2008).

Já para o parênquima esponjoso foi notado nas cultivares MGS Grapollo 556, MGS Grapollo 561 maiores valores, contrariamente a cultivar MGS Mariense, com menor espessura. Em adição, os resultados demonstraram que o parênquima esponjoso apresenta espessura superior ao parênquima paliçádico em todas as plantas estudadas.

Tabela 2. Espessura média de tecidos foliares, mesofilo e nervura central (em $\mu \mathrm{m})$ em cultivares de oliveira (Olea europaea L.).

\begin{tabular}{lllllll}
\hline Cultivares & EAB & EAD & EPP & EPE & EM & ENC \\
\hline MGS Grapollo 556 & $28,25 \mathrm{~b}$ & $41,31 \mathrm{a}$ & $367,60 \mathrm{a}$ & $640,91 \mathrm{a}$ & $1081,38 \mathrm{a}$ & $1648,09 \mathrm{a}$ \\
MGS Neblina & $28,66 \mathrm{~b}$ & $31,53 \mathrm{~b}$ & $238,93 \mathrm{c}$ & $548,27 \mathrm{~b}$ & $888,98 \mathrm{~b}$ & $1593,52 \mathrm{~b}$ \\
MGS Grapollo 541 & $31,78 \mathrm{a}$ & $32,51 \mathrm{~b}$ & $233,45 \mathrm{c}$ & $567,77 \mathrm{~b}$ & $882,19 \mathrm{~b}$ & $1309,58 \mathrm{c}$ \\
MGS Grapollo 561 & $32,50 \mathrm{a}$ & $40,00 \mathrm{a}$ & $357,00 \mathrm{a}$ & $655,50 \mathrm{a}$ & $1094,00 \mathrm{a}$ & $1640,04 \mathrm{a}$ \\
MGS Mission 293 & $31,00 \mathrm{a}$ & $35,75 \mathrm{~b}$ & $302,00 \mathrm{~b}$ & $558,50 \mathrm{~b}$ & $934,07 \mathrm{~b}$ & $1323,55 \mathrm{c}$ \\
MGS Mariense & $25,00 \mathrm{a}$ & $29,00 \mathrm{~b}$ & $357,50 \mathrm{a}$ & $459,50 \mathrm{c}$ & $887,00 \mathrm{~b}$ & $1338,08 \mathrm{c}$ \\
\hline CV (\%) & 7,38 & 7,82 & 6,32 & 5,73 & 7,82 & 2,7 \\
\hline
\end{tabular}

$\mathrm{EAB}=$ espessura da epiderme da face abaxial, EAD $=$ espessura da epiderme da face adaxial, $\mathrm{EPP}=$ espessura do parênquima paliçadico, $\mathrm{EPE}=$ espessura do parênquima esponjoso, $\mathrm{EM}=$ espessura do mesofilo, $\mathrm{ENC}=$ espessura da nervura central. Grupo de médias seguidas pela mesma letra na coluna não diferem entre si pelo teste de Skott-knott $(p<0,05)$.

Com relação a espessura do mesofilo e da nervura central, as cultivares MGS Grapollo 556 e MGS Grapollo 561 apresentaram maiores espessamentos. Assim, estas duas cultivares podem ser consideradas mais eficientes fotossinteticamente, pois de acordo com Gomes et al. (2009), quanto maior a espessura ou o número de camadas celulares do mesofilo, maior a eficiência da fotossíntese.

Acrescenta-se ainda que estudos em diferentes condições climáticas são necessários para verificar a plasticidade das folhas de oliveira.

\section{Conclusão}

O conteúdo de DNA das cultivares de oliveiras variaram de 2,54 a 2,89 pg apresentando uma pequena amplitude.

A estrutura básica das cultivares de oliveiras é a mesma, porém há distinção nas espessuras dos tecidos foliares, na nervura central e no mesofilo, o que provavelmente permite a adaptação dessas cultivares em diferentes ambientes.

\section{Agradecimentos}

Os autores agradecem à Fundação de Amparo a Pesquisa do Estado de Minas Gerais 


\section{(요 \\ Revista Agrarian \\ ISSN: 1984-2538}

(FAPEMIG) pelo apoio financeiro dado para a execução deste trabalho.

\section{Referências}

CANÇADO, G. M. A.; SANTANA, G. C.; VAL, A. D. B. do; FERREIRA, J. L. Marcadores moleculares de DNA e suas aplicações na caracterização, identificação e melhoramento genético da oliveira.. In: Adelson Francisco de Oliveira. (Org.). Oliveiras no Brasil: tecnologias de produção.. 1ed.Belo Horizonte: EPAMIG, 2012, v. 1, p. 225-249.

CASTRO, E. M.; PEREIRA, F. J.; PAIVA, R. Histologia Vegetal: estrutura e função dos órgãos vegetativos. Lavras: UFLA, 2009. 234 p.

GALBRAITH, D. W, LAMBERT, G. M, MACAS, J, DOLEŽEL. J. 2002. Analysis of nuclear DNA content and ploidy in higher plants. In: Robinson JP, Darzynkiewicz Z, Dean PN, Dressler LG, Rabinovitch PS, Stewart CV, Tanke HJ, Wheeless LL, eds. Current protocols in cytometry. New York: John Wiley \& Sons, 7.6.17.6.22.

GOMES, A. A.; PASQUAL, M.; MIYATA, L. Y.; CASTRO, E. M.; ROCHA, H. S. Qualidade de luz na biometria e anatomia foliar de plântulas de Cattleya loddigesii L. (Orchidaceae) micropropagadas. Ciência Rural, Santa Maria, v. 39, n. 9, p. 2506-2511, 2009.

LEAL-COSTA, M. V.; ARAGÃO, F. J. L.; REINERT, F.;, TAVARES, E. S. Anatomia foliar de plantas transgênicas e não transgênicas de Glycine $\max$ (L.) Merrill (Fabaceae). Revista Biociências, UNITAU, n. 1, v. 14, p. 23-31, 2008.

LOUREIRO, J.; RODRIGUEZ, E.; COSTA, A.; SANTOS, C. Nuclear DNA content estimations in wild olive (Olea europaea L. ssp. europaea var. sylvestris Brot.) and Portuguese cultivars of $\mathrm{O}$. europaea using flow cytometry. Genet Resour Crop Evol. v. 54, p. 21-25, 2007.

MORETTI, S.; FRANCINI, A.; MINNOCCI, A.; SEBASTIANI, L. Does salinity modify anatomy and biochemistry of Olea europaea L. fruit MARK during ripening? Scientia Horticulturae. v. 228, p. 33-40, 2017.

OLIVEIRA, A. F.; VIEIRA NETO, J.; GONÇALVES, E. D.; MESQUITA, D. L.
Pioneirismo marca pesquisa sobre oliveira em Minas Gerais. Informe Agropecuário, Belo Horizonte, v. 30, p. 7-15, 2009.

SCHIFINO-WITTMANN, M. T. Determinação da quantidade de DNA nuclear em plantas. Ciência Rural. v. 31, n. 5, p. 897-902, 2001.

SILVA, L. M.; ALAQUINI, Y.; CAVALLET, V. J. Inter-relações entre a anatomia vegetal e a produção vegetal. Acta Botanica Brasilica, Porto Alegre, v. 19, p. 183-194, 2005.

TUFFI SANTOS, L. D.; SANT'ANNA-SANTOS, B. F.; MEIRA, R. M. S. A.; TIBURCIO, R. A. S.; FERREIRA, F. A.; MELO, C. A. D.; SILVA, E. F. S. Danos visuais e anatômicos causados pelo glyphosate em folhas de Eucalyptus grandis. Planta Daninha, v. 26, p. 9-16. 2008.

WILLIAMS, B. R..; MIRZOEVA, O. K.; MORGAN, W. F.; LIN, J.; DUNNICK, W.; PETRINI, J. H. A murine model of Nijmegen breakage syndrome. Current Biology, London, v. 12, n. 8, p. 648-653, 2002. 